\title{
NOVEL DEVICE TO MEASURE BODY LENGTH AT AUTOPSY
}

\author{
Fernando D.M.G. ${ }^{1}$, Gunatilake P.G.L. ${ }^{2}$ \\ ${ }^{1}$ Senior lecturer, ${ }^{2}$ Senior Staff Technical Officer, Dept. of Forensic Medicine, \\ Faculty of Medicine, University of Peradeniya, Sri Lanka.
}

\begin{abstract}
Every text book or manual on autopsy procedure instructs that the length of the body is to be measured at every post mortem examination conducted. However, how, and with what instrument, this is to be carried out is not described. An internet search failed to find resources describing the technique; nor could any images of an appropriate instrument to measure body length at autopsy, or videos demonstrating the technique, be found. The method of ascertaining the length of the body varies from place to place. Either they are not accurate, require two operators for an accurate reading, or require the use of a cumbersome instrument. Therefore, the authors invented, and have successfully used, an accurate, low cost, small device which is simple to use by a single operator, to measure the length of bodies at autopsy. A detailed description of the device, and method of using, to obtain an accurate length is given for the benefit of those carrying out pathological, coronial or forensic autopsies.
\end{abstract}

Key words: Post-mortem, Length, Measurement, Portable, Instrument.

Corresponding author:

dineshmgfdo@yahoo.com

\section{INTRODUCTION}

Every text book or manual on autopsy procedure mentions that the heel to crown length of every deceased that undergoes a forensic autopsy has to be measured and recorded [1,2]. The body length is part of every autopsy report and is important, together with the weight, for the court to have an idea about the stature of the person. This is especially important in suspicious deaths, hanging, homicides and sexual offences. Surprisingly, an internet search did not reveal any literature on how this is to be specifically done; neither was there any images of an instrument to measure length of a body at autopsy or videos demonstrating the technique.

\section{OBJECTIVE}

To design a low cost, small, lightweight, portable device, to accurately measure body length at autopsy, by a single operator.

\section{MATERIALS AND METHOD}

The device consists of a three sided rectangular box into which the feet are placed. There is an extension arm at the level of the heel, into which the hook of the retractable $3 \mathrm{~m}$ steel tape is inserted (Figure 1). 


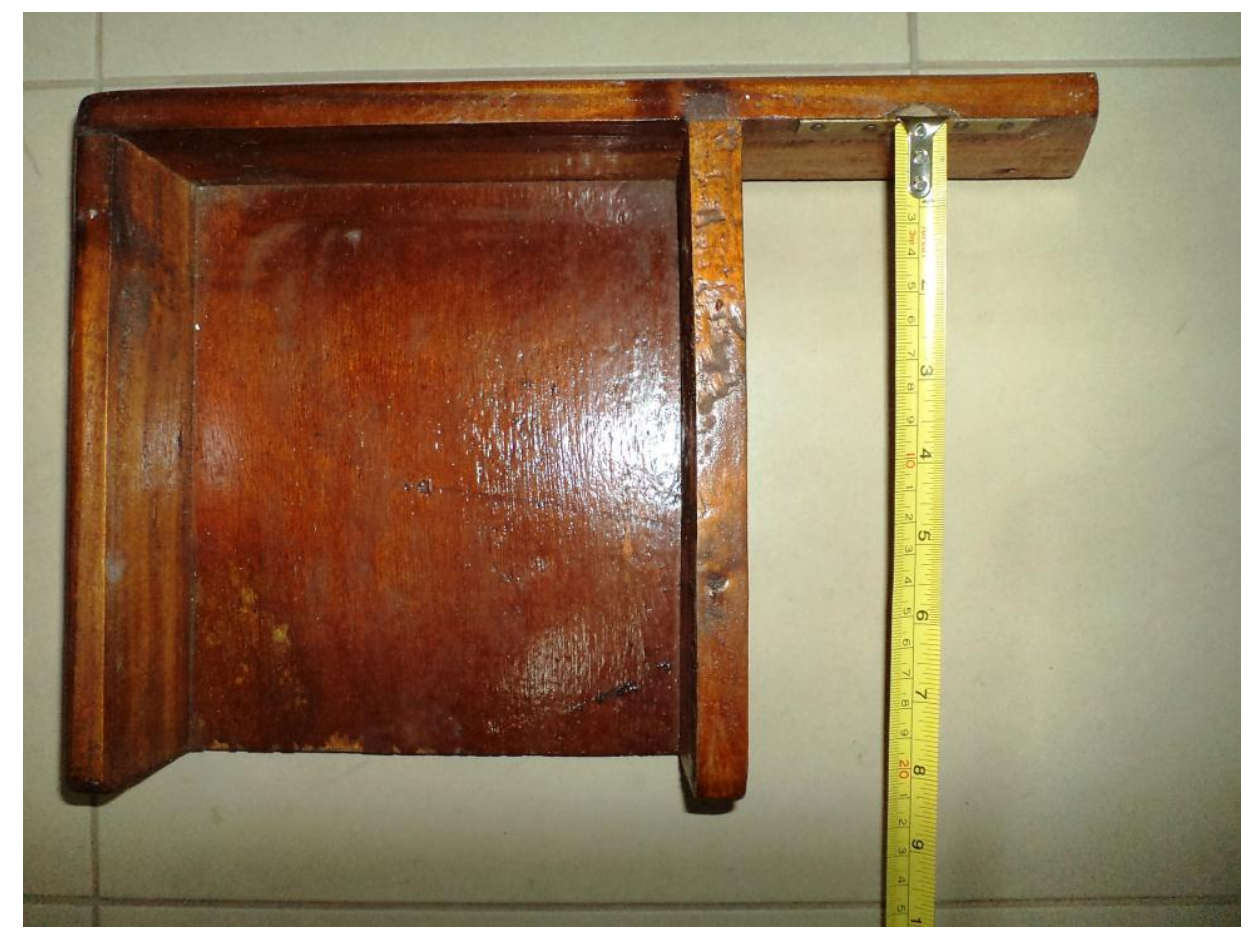

Figure 1: The device with steel measuring tape hooked on the extension arm

The tape is drawn out parallel to the body and the autopsy ruler is placed on the crown of the head perpendicular to the steel tape (Figure 2). The reading is taken at this point.

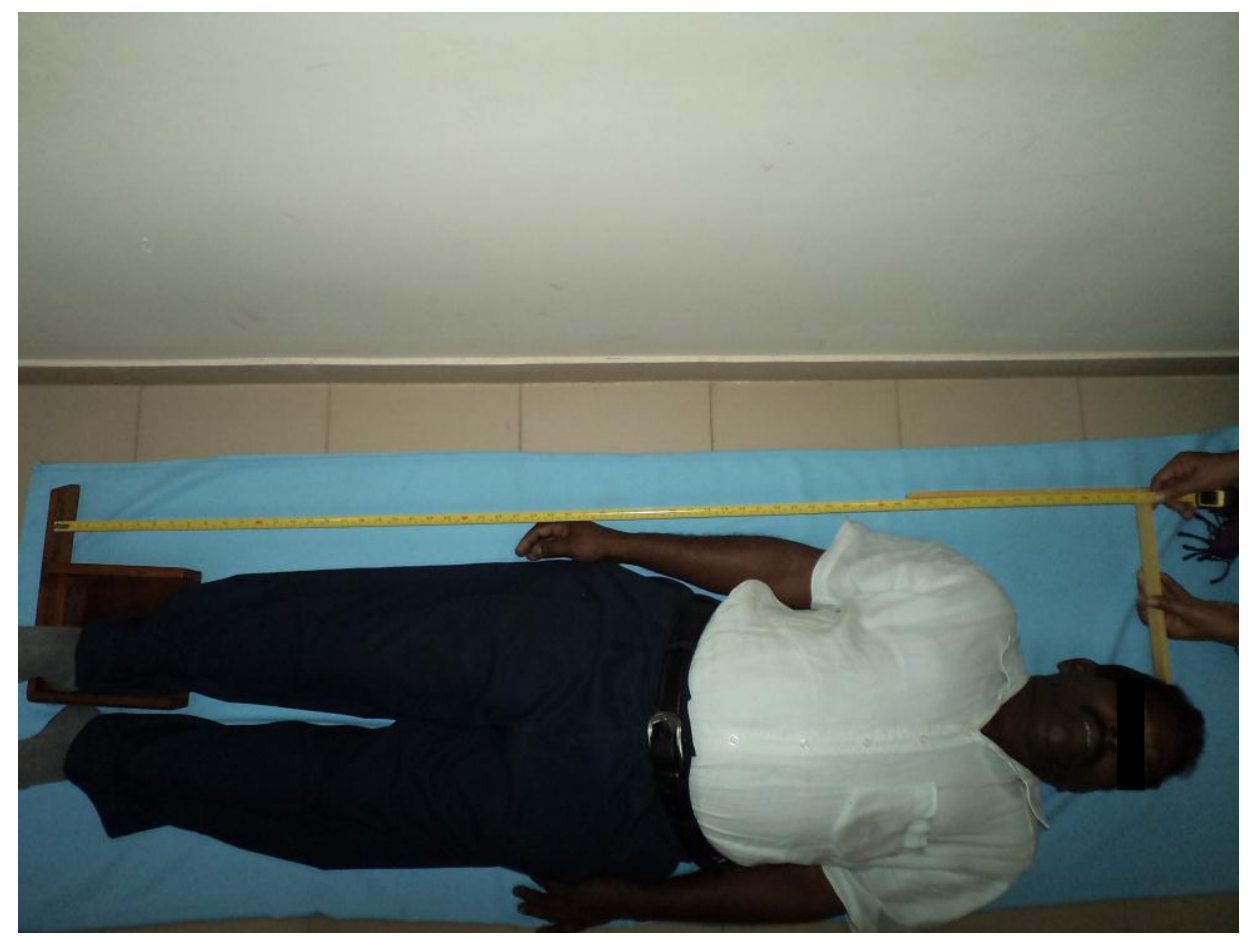

Figure 2: A single operator using the device to obtain an accurate length in a volunteer

The error caused by the ruler not being at right angles to the tape can be minimised by using a commercial tri set square or two pieces of wood or plastic placed at right angles to each other (Figure 3). 


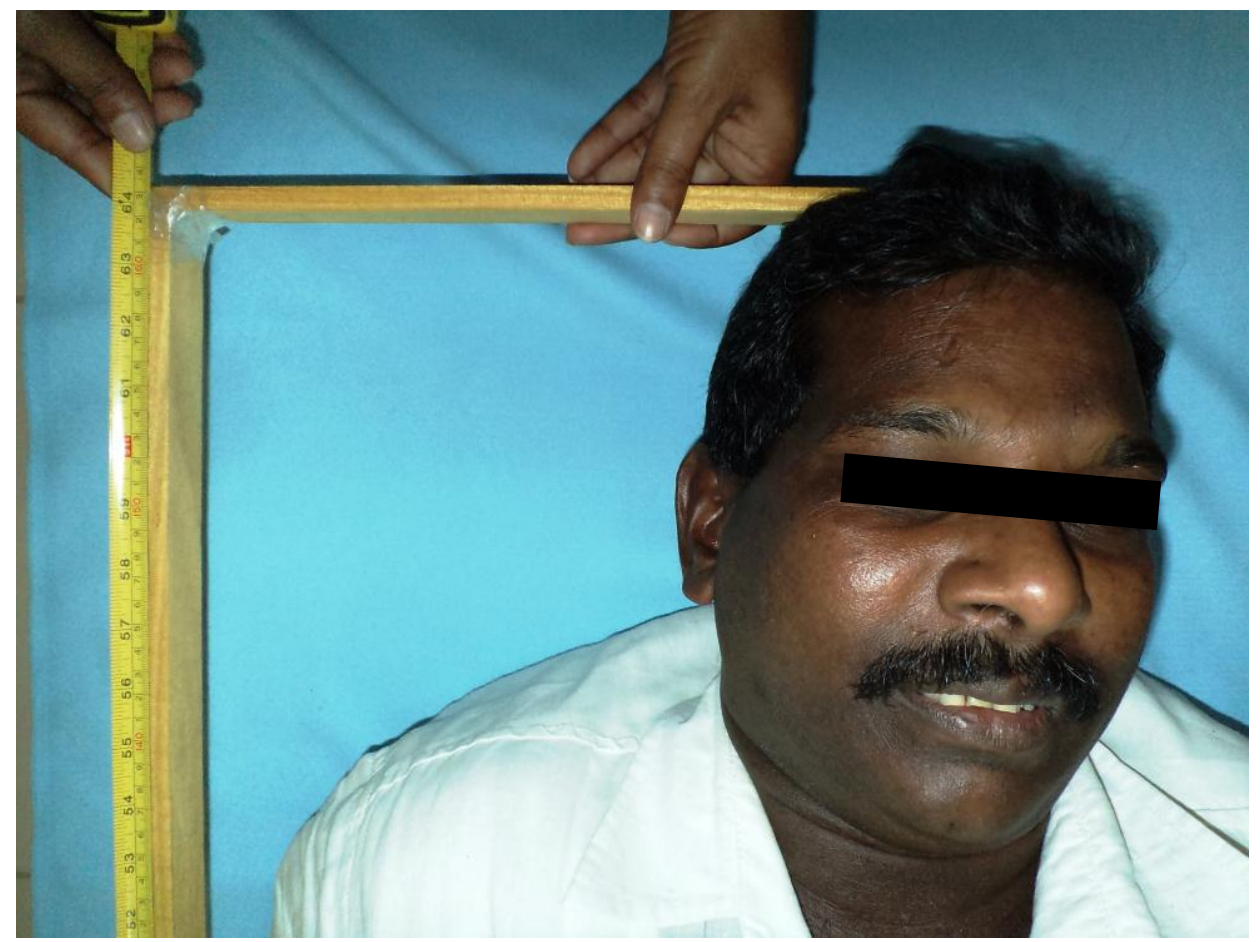

Figure 3: Reading taken at the head parallel to the heel at right angles to the tape

The device can be made from wood, plastic or fibreglass and measures $30 \times 20 \times 6 \mathrm{~cm}$. The retractable steel tape can be purchased in any store and measures $7 \times 7 \times 3 \mathrm{~cm}$.

\section{DISCUSSION}

The method and instrument used to measure body length varies from place to place. One instrument used is an "L" shaped rigid rod with a scale $2 \mathrm{~m}$ in length with a fixed head piece at right angles to zero on the scale. The length of the body is measured by placing the head piece on top of the head and placing the autopsy ruler parallel to the head piece on the heel and taking the reading where it meets the $2 \mathrm{~m}$ scale. A modification of this instrument, to reduce the error of the ruler not being held parallel to the head piece, is to have a sliding foot piece attached at right angles to the long limb. This instrument is accurate and measurement can be done by a single person. However, it is cumbersome to use, transport and store. Another method is to use a plastic tape placed alongside the body. However, two operators are required; one to hold the tape at the level of the top of the head (crown) while the other takes a similar reading at the heel. Even though a plastic tape is small and easily transportable this method is prone to errors since the tape is placed some distance away from the top of head and heel along the autopsy table, along the widest point of the body - the shoulders or hips. Therefore, there is a chance of error when ascertaining the level at head and heel, especially if the total length of the tape is less than the body length. If the tape is placed along the surface of the body, from head to toe, the error is intensified. Not only does the tape follow the contours of the anterior aspect of the body, but also, this measurement is the undertaker's length (as it is head to toe) and may be several centimetres more than the crown to heel length. The use of the autopsy foot ruler is even worse as the margin of error is very much greater.

The above device can be used at autopsies conveniently and easily, even by a single person, with a high degree of accuracy. In 
addition, the size makes it easily transportable to a scene, or to conduct an autopsy in another location. An added advantage, especially for resource poor developing countries, is that it can be easily manufactured locally at very minimal cost. It is hoped that publication will disseminate this information far and wide. The authors have not patented this post mortem body length measuring device to enable anyone to reproduce, use and improve it for the benefit of society.

\section{ACKNOWLEDGEMENTS}

The assistance of Mr. Sahadevan of the department of Forensic Medicine, Faculty of Medicine, University of Peradeniya for posing for the photographs is gratefully acknowledged.

\section{DISCLOSURES}

A poster presentation on the above device titled 'Novel device to measure body length at autopsy', was done at the $10^{\text {th }}$ Indo Pacific Congress on Legal Medicine and Forensic Sciences, held in New Delhi, India from 25-30 October 2010.

\section{FUNDING}

Not obtained from any source.

\section{CONFLICT OF INTEREST}

Fernando DMG declares he has no conflict of interest.

Gunatilake PGL declares he has no conflict of interest.

\section{REFERENCES}

1. Knight B, Saukko P. Knight's Forensic Pathology. $4^{\text {th }}$ ed. Florida, CRC Taylor \& Francis. 2016:14.

2. Connolly AJ, Finkbeiner WE, Ursell PC, Davis RL. Autopsy Pathology: a manual and atlas $3^{\text {rd }}$ ed. Philadelphia, Elsevier. 2016:34. 